\title{
Failure of an uncemented non-porous metal- backed prosthesis with augmentation using impacted allograft for acetabular revision
}

(a)

\author{
12- TO 17-YEAR RESULTS \\ M. Jeffery, G. Scott, M. Freeman \\ From the Royal London Hospital, England
}

W e have reviewed 29 patients (30 hips) who had undergone revision total hip arthroplasty using a Freeman metal-backed acetabular component and acetabular impaction allografting. The mean follow-up was for 15.3 years (12 to 17).

Five patients ( 5 hips) died with the prosthesis in situ and four (4 hips) were lost to follow-up. Twelve hips had failed and in the remaining nine there were minor symptoms. The mean time to failure requiring further surgery was nine years. Excluding patients who were lost to follow-up or had died, $72 \%$ of the hips were radiologically loose at the last review. The commonest pattern in those requiring revision was failure of the reinforcement ring in adduction with remodelling of the medial wall.

Of the nine patients who had not undergone revision, one with bilateral replacements had no current radiographs and only three of the remaining seven replacements had no radiological signs of loosening.

The short-term results for this technique have been reported to be satisfactory, but in the long term they are not. The factors associated with failure include the design of the prosthesis, which has been implicated in disappointing long-term results when used in primary arthroplasty, but not with the frequency of failure found in this series. It seems that the reliance on peripheral screw fixation over a bed of allograft without bridging the graft does not provide sufficient stability to allow incorporation of the graft.

J Bone Joint Surg [Br] 2003;85-B:182-6.

Submitted: 8 February 2002; Accepted: 11 June 2002

M. Jeffery, FRCS, Orthopaedic Registrar

G. Scott, FRCS, Consultant Orthopaedic Surgeon

M. Freeman, MD, FRCS, Consultant Orthopaedic Surgeon

Bone and Joint Research Unit (Orthopaedic Section), 3rd Floor Pathology Institute, Royal London Hospital, Whitechapel, London E1 1BB, UK.

Correspondence should be sent to Mr M. Jeffery.

(C)2003 British Editorial Society of Bone and Joint Surgery doi.10.1302/0301-620X.85B2.13249 \$2.00
Failure of hip arthroplasty usually involves the acetabular component and revision is often difficult because of loss of host bone. ${ }^{1}$ An attempt to resolve this problem by using homograft bone and a shot-blast cementless metal-backed acetabular component was described in an early publication from this institution. ${ }^{2}$ This was the first report of which we are aware of cementless revision with an allograft. The early results were excellent, but the long-term outcome was unknown. We now report the long-term outcome of patients treated in this manner.

\section{Patients and Methods}

We have followed 29 patients (30 hips) seen at the UK centre of an original two-centre study for between 12 and 17 years. This group includes all the UK patients from the original report and further patients who were operated on using the same technique until the implant was superseded. There were 19 women (20 hips) and 10 men (10 hips) who were mainly affected by osteoarthritis (Table I). Their mean age was 49 years (30 to 78). The primary implant was a resurfacing arthroplasty in 23 hips. The remainder were other failed primary total hip arthroplasties or hemiarthroplasties. The acetabular defects found at revision were classified using the system of the American Academy of Orthopaedic Surgeons (AAOS) ${ }^{3}$ (Table II).

All patients were seen and assessed before and at three and six months after operation and thereafter annually for five years. Subsequently, reviews took place every two years unless there was clinical concern. In those patients who found attendance difficult a telephone interview was carried out and locally acquired radiographs were analysed. If patients had undergone revision elsewhere details were obtained from those who had treated them.

The assessment was carried out using a standard proforma recording pain, maximum uninterrupted walking ability (in minutes), functional ability and a clinical examination. The radiographs were studied for evidence of loosening based on the criteria described by Sutherland et $\mathrm{al}^{4}$ and features noted by Massin, Schmidt and Engh $^{5}$ and Haentjens et al, ${ }^{6}$ including radiolucent lines and their progression. Migration of the prosthesis, both horizontally and vertically, was measured by a digitiser according to the method of Nunn et al. ${ }^{7}$ The number and location of screws 
Table I. The initial diagnoses for the 29 patients (30 hips) who underwent revision total hip arthroplasty

\begin{tabular}{ll}
\hline Primary diagnosis & Number of hips \\
\hline Osteoarthritis & 18 \\
Rheumatoid arthritis & 2 \\
Ankylosing spondylitis & 2 \\
Avascular necrosis & 1 \\
Developmental dysplasia & 3 \\
Post-traumatic arthritis & 4
\end{tabular}

and any change of the angle of inclination of the acetabular component were noted. This angle was measured from the intersection of a line connecting the two most peripheral points of the component and the interteardrop line. All measurements were taken from standardised pelvic anteroposterior radiographs centred $2.5 \mathrm{~cm}$ above the symphysis pubis with a source-to-plate distance of $1 \mathrm{~m}$.

Operative technique. Using a modified anterolateral approach to the hip, the loose components and wear debris were removed to expose healthy host bone. ${ }^{8}$ A trial component was inserted to assess the appropriate size, aiming to fit
Table II. The relationship of the AAOS classification to failure of total hip arthroplasty after cementless revision with an allograft, by number and percentage

\begin{tabular}{lclc}
\hline AAOS type & Number & Revised & Percentage \\
\hline I s & 1 & 1 & 100.0 \\
I s+p & 1 & 0 & 0.0 \\
I c & 3 & 0 & 0.0 \\
II s & 10 & 7 & 70.0 \\
II s+p & 3 & 2 & 66.0 \\
II c & 6 & 1 & 16.6 \\
III & 5 & 2 & 40.0 \\
IV & 1 & 0 & 0.0 \\
\hline
\end{tabular}

the acetabular cavity and provide at least $50 \%$ of host contact in order to provide stability. ${ }^{9}$ The acetabular cavity was packed with morsellised fresh-frozen bone prepared in a guillotine mill producing particles of 3 to $5 \mathrm{~mm}$ in size. The fragments were compressed using a combination of the trial prosthesis and the reamer both of which were hammered to increase impaction. The aim was to place the graft no more than $1 \mathrm{~cm}$ from living bone. If necessary a larger fragment was used to fill the medial wall of the acetabulum.

The support ring was inserted using up to six AO screws placed peripherally through sliding holes in the metal back.

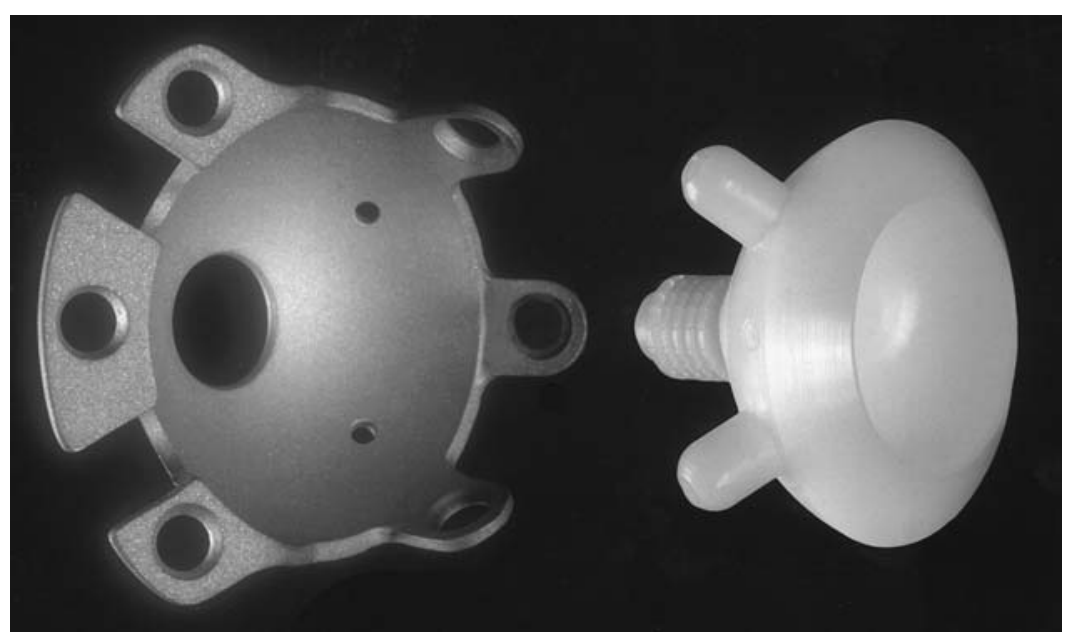

Fig. 1

Photograph of the Freeman design 'press-fit' prosthesis.

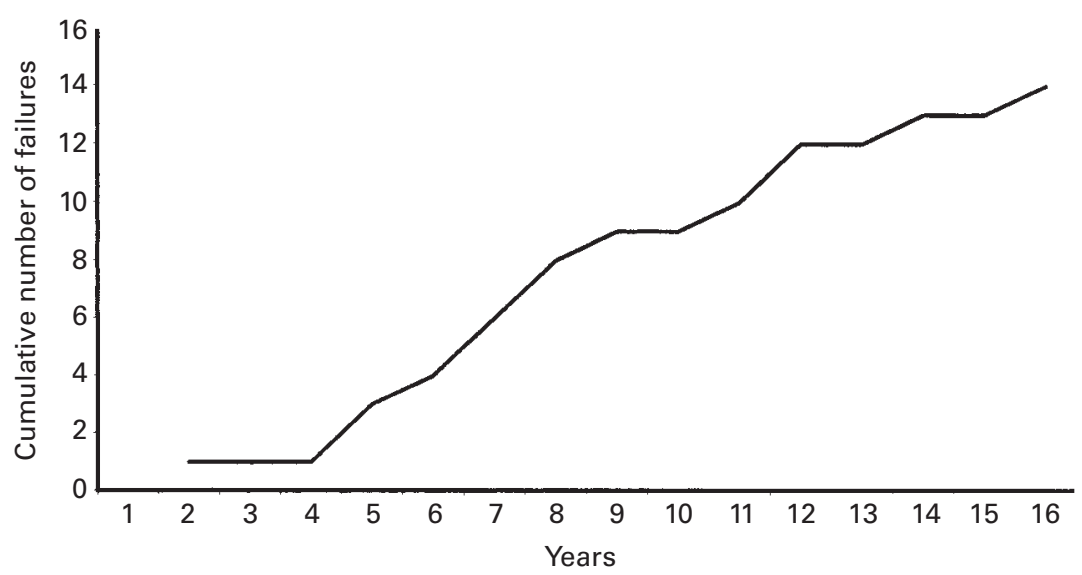

Fig. 2

Graph of cumulative number of failures against time. 


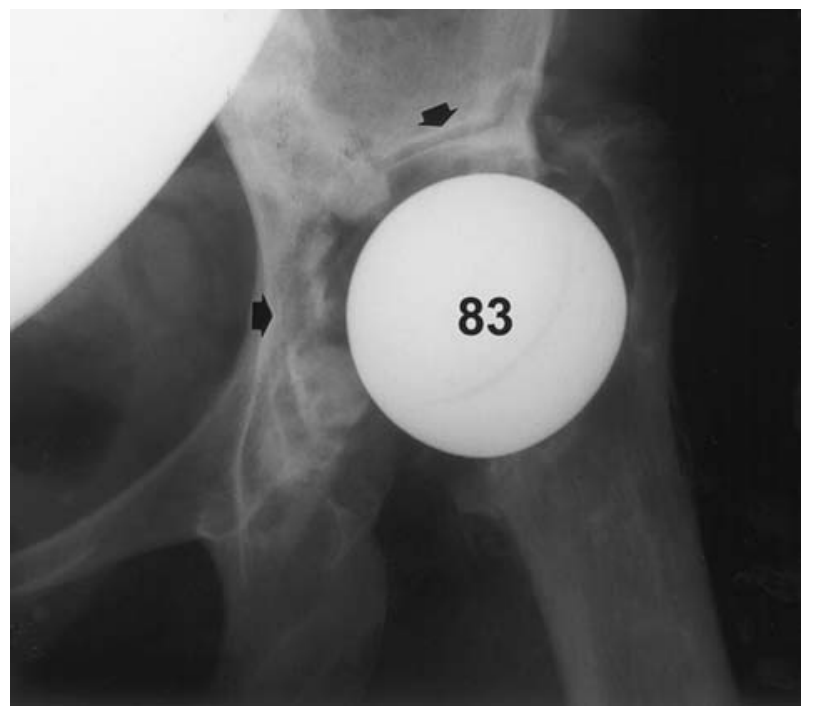

Fig. 3a

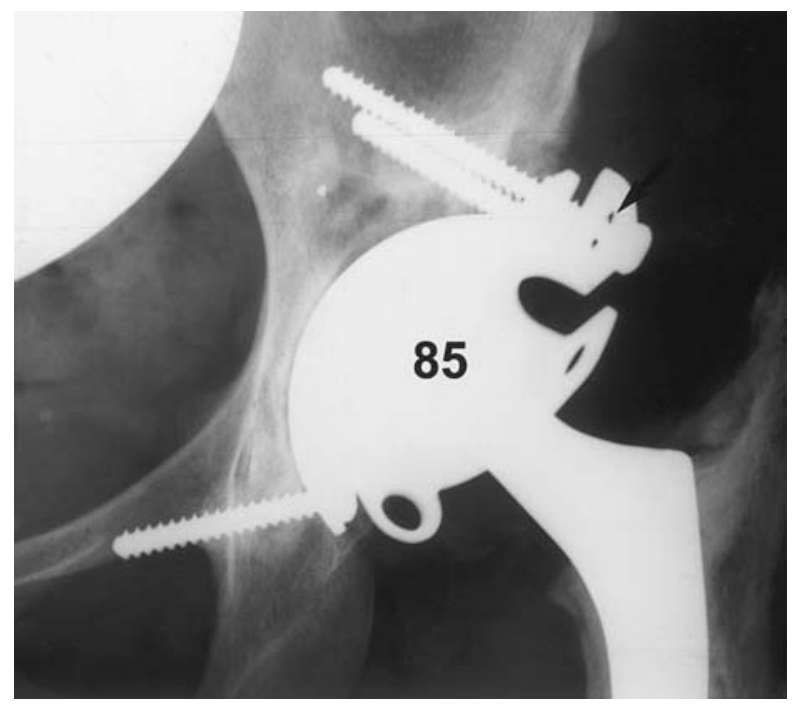

Fig. 3c

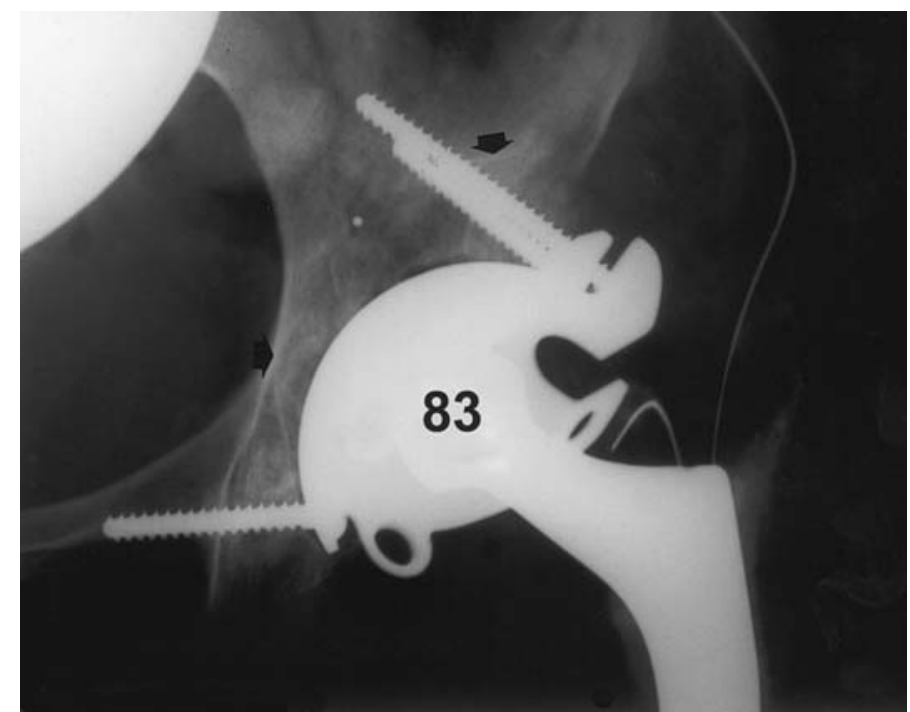

Fig. 3b

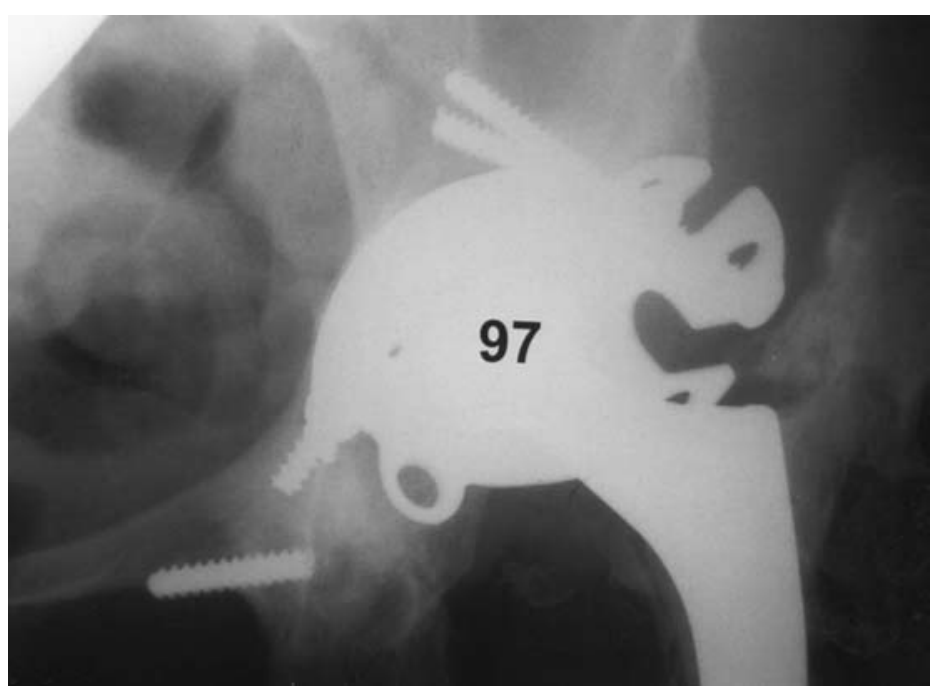

Fig. 3d

Radiographs showing a typical pattern of failure. Figure $3 \mathrm{a}$-- The preoperative appearance of a failed surface replacement. The arrows mark the limits of bone loss. Figure 3b -- Immediately after surgery. The arrows denote the limit of the host bone. Figure $3 \mathrm{c}--$ Two years after operation there is superior migration of the acetabular component in the graft bed with loosening around the marked screw. Figure $3 \mathrm{~d}$-- At 12 years after surgery, there is failure with migration, alteration of acetabular inclination and breakage of a screw.

The component used was a Freeman revision press-fit cup (Corin Medical, Cirencester, UK) with a grit-blasted cobaltchrome backing and a pegged clip-in polyethylene insert (Fig. 1). The polyethylene liner had an internal diameter of $32 \mathrm{~mm}$

\section{Results}

Four patients (4 hips) were lost to follow-up at two, two, five and 11 years. At their last review, none had symptomatic evidence of loosening. Of the remaining 25 patients, five (5 hips) had died with the prosthesis in situ at five, six, six, nine and 11 years. Ten patients (10 hips) had been revised and two more ( 2 hips) are awaiting revision. In eight patients (9 hips) the prosthesis was in situ and there were minor symptoms which were controlled by simple analgesia.

The mean time to further revision was nine years ( 2 to 14). Only one hip failed before five years. The remaining 11 hips were revised or are awaiting revision for aseptic loosening. The rate of failure for the whole group was thus $40 \%$ (12 of 30). If those who were lost to follow-up or who had died were excluded the rate of failure was $57 \%$ (12 of 21). A graph of the cumulative number of further revisions against 
Table III. The number of observed radiological features of loosening in the 12 hips which underwent or are awaiting revision

\begin{tabular}{ll}
\hline Feature of loosening & Number \\
\hline Migration $5 \mathrm{~mm}$ & 6 \\
Breakage/erosion of screws & 6 \\
Progressive radiolucent lines & 7 \\
Change in inclination angle & 7 \\
\hline
\end{tabular}

time shows the increasing failure rate after five years (Fig. 2).

There was no relationship between the severity of the AAOS classification, the number of screws used, the initial diagnosis and the time to failure. A comparison of age at revision and the time to failure of the replacement for patients aged over 50 years ( 2 to 7 hips) with those under 50 years (10 of 14 hips) did not show a statistically significant relationship (Fisher's exact test, $\mathrm{p}=0.15$ ).

Radiological analysis. Evidence of radiological loosening was defined as horizontal or vertical migration of the component by $5 \mathrm{~mm}$ or more, progressive radiolucent lines and damage or breakage of screws. Of the 18 hips which were available for review, 13 showed signs of loosening.

Of the eight patients ( 9 hips) with their implants in situ who have minor symptoms, one with bilateral revision arthroplasties had no current radiographs. Of the remaining seven patients (7 hips) only three had no radiological evidence of loosening at a minimum follow-up of 12 years.

Most hips failed with the component migrating medially and 'closing' by rotation in a direction equivalent to adduction. The inclination angle of the component changed by more than $5^{\circ}$ in $70 \%$ of those which were available for analysis (Fig. 3). Analysis of the 12 hips which were revised or awaiting revision showed a mean migration horizontally of $4.7 \mathrm{~mm}$ and vertically of $8.8 \mathrm{~mm}$ before further revision. The features of loosening in these patients are summarised in Table III. Two patients had no radiological evidence of loosening at revision, one had recurrent dislocation and the other had a revision for femoral loosening when the acetabular component was also found to be loose.

\section{Discussion}

Impaction bone grafting of the acetabulum in arthroplasty of the hip was described by Hastings and Parker ${ }^{10}$ and popularised by Slooff et $\mathrm{al}^{11}$ in primary and revision hip arthroplasty using autograft and allograft bone. When used in revision arthroplasty a survival of about $90 \%$ has been reported, but only at a mean follow-up of seven years. ${ }^{12-15}$ The radiological results in these reports describe good incorporation of the bone graft, although this has not always been consistent with the results of histological examination. ${ }^{16}$ There have also been encouraging early results using bone substitutes and uncemented devices. ${ }^{17,18}$ Only two long-term studies, however, have been undertaken for revised acetabula. Schreurs et $\mathrm{al}^{19}$ using cement and impacted allograft and Wachtl et $\mathrm{al}^{20}$ using impacted allograft with an antiprotrusio cage, report survivorship exceeding $90 \%$ at a follow-up of approximately 12 years. Our long-term results are markedly inferior to these. Failure in our patients presented after five years, although satisfactory results had been seen at a mean of 1.5 years. ${ }^{2}$ Caution should be observed when reporting the results of acetabular impaction allografting with a follow-up of less than ten years. A similar problem was noted by Harris ${ }^{21}$ and Kwong, Jasty and Harris ${ }^{22}$ with bolted structural allografts. There are a number of factors which could have contributed to the high rate of failure including features related to the implant and to the technique.

In primary replacement, a similar acetabular implant has given disappointing results with survival ranging from $69 \%$ at five years ${ }^{23}$ to $83 \%$ at ten years. ${ }^{24}$ The press-fit nature of the polyethylene insert into the metal backing allows some micromovement between the respective parts. This provides a source of wear particles which produce an inflammatory reaction causing loosening. A $32 \mathrm{~mm}$ diameter head as used in our study, except in the illustrative case shown in Figure 3 , has been implicated in a higher rate of wear. ${ }^{25}$ These adverse design features are shared with the revision implant used in our series. Our results were, however, particularly poor. Both the timing and degree of failure suggest that additional factors are involved. A metal-backed shell made of grit-blasted cobalt-chrome secured with peripheral screws in conjunction with small particles of allograft did not provide enough stability to allow incorporation of the graft. The surface finish of the metal back was not conducive to bone ongrowth where it was in contact with host bone and where bridging of the graft was required for superolateral defects.

The pieces of bone graft which were used may have been too small to be impacted sufficiently to allow the compression and stability which are essential for revascularisation. Schreurs et $\mathrm{al}^{19}$ used larger pieces of allograft. These provided some intrinsic strength on impaction which may have aided incorporation.

Long-term follow-up is essential in the assessment of revisions involving bone allograft. The initial report of this acetabular component was published prematurely. ${ }^{2}$ Success in acetabular impaction allografting is dependent on fragments of appropriate size and an implant which ensures a suitable environment for revascularisation. The prosthesis used in our series failed to confer sufficient stability for incorporation of the graft.

No benefits have been received or will be received from a commercial party related directly or indirectly to the subject of this article.

\section{References}

1. Wroblewski BM, Siney PD. Charnley low friction arthroplasty of the hip: long-term results. Clin Orthop 1993;292:191-201.

2. Samuelson KM, Freeman MAR, Levak B, Rassmussen GL, Revell PA. Homograft bone in revision acetabular arthroplasty: a clinical and radiographic study. J Bone Joint Surg [Br] 1988;70-B:367-72. 
3. D'Antonio JA, Capello WN, Borden LS, et al. Classification and management of acetabular abnormalities in total hip arthroplasty. Clin Orthop 1989;243:126-37.

4. Sutherland CJ, Wilde AH, Borden LS, Marks KE. A ten-year followup of one hundred consecutive Müller curved-stem total hip-replacement arthroplasties. J Bone Joint Surg [Am] 1982;64-A:970-82.

5. Massin P, Schmidt L, Engh CA. Evaluation of cementless acetabular component migration: an experimental study. $J$ Arthroplasty 1989;4:245-51.

6. Haentjens P, de Boeck H, Handelberg F, Casteleyn P, Opdecam P. Cemented acetabular reconstruction with the Muller support ring: a minimum five-year clinical and roentgenographic follow-up study. Clin $\mathrm{Or}$ thop 1993;290:225-35

7. Nunn D, Freeman MAR, Hill PF, Evans SJW. The measurement of migration of the acetabular component of hip prostheses. $J$ Bone Joint Surg [Br] 1989;71-B:629-31.

8. Stephenson PK, Freeman MAR. Exposure of the hip using a modified anterolateral approach. J Arthroplasty 1991;6:137-45.

9. Hooten JP Jr, Engh CA Jr, Engh CA. Failure of structural acetabular allografts in cementless revision hip arthroplasty. J Bone Joint Surg [Br] 1994;76-B:419-22.

10. Hastings DE, Parker SM. Protrusio acetabuli in rheumatoid arthritis. Clin Orthop 1975;108:76-84.

11. Slooff TJ, Huiskes R, Van Horn J, Lemmens AJ. Bone grafting in total hip replacement for acetabular protrusion. Acta Orthop Scand 1984;55:593-6.

12. Rosson J, Schatzker J. The use of reinforcement rings to reconstruct deficient acetabula. J Bone Joint Surg [Br] 1992;74-B:716-20.

13. Gill TJ, Sledge JB, Muller ME. The management of severe acetabular bone loss using structural allograft and acetabular reinforcement devices. J Arthroplasty 2000;15:107.

14. Haddad FS, Shergill N, Muirhead-Allwood SK. Acetabular reconstruction with morcellized allograft and ring support: a medium term review. J Arthroplasty 1999;14:788-95.
15. Zehntner MK, Ganz R. Midterm results (5.5 to 10 years) of acetabular allograft reconstruction with the acetabular reinforcement ring during total hip revision. J Arthroplasty 1994;9:469-79.

16. Hooten JP, Engh CA, Heekin RD, Vinh TN. Structural bulk allografts in acetabular reconstruction: analysis of two grafts retrieved at postmortem. J Bone Joint Surg [Br] 1996;78-B:270-5.

17. Oonishi H, Iwaki Y, Kin N, et al. Hydroxyapatite in revision of tota hip replacements with massive acetabular defects: 4 to 10-year clinica results. J Bone Joint Surg [Br] 1997;79-B:87-92.

18. Buoncristiani AM, Dorr LD, Johnson C, Wan Z. Cementless revision of total hip arthroplasty using the anatomic porous replacement revision prosthesis. J Arthroplasty 1997;12:403-15.

19. Schreurs BW, Slooff TJJH, Buma P, Huiskes R. Acetabular reconstruction with impacted morsellised cancellous bone graft and cement: a 10- to 15-year follow-up of 60 revision arthroplasties. J Bone Joint Surg [Br] 1998;80-B:391-5.

20. Wachtl SW, Jung M, Jakob RP, Gautier E. The Burch-Schneider antiprotrusio cage in acetabular revision surgery: a mean follow-up of 12 years. J Arthroplasty 2000;15:959-63.

21. Harris WH. Allografting in total hip arthroplasty: in adults with severe acetabular deficiency including a surgical technique for bolting the graft to the ilium. Clin Orthop 1982;162:150-64.

22. Kwong LM, Jasty M, Harris WH. High failure rate of bulk femoral head allografts in total hip acetabular reconstructions at 10 years. $J$ Arthroplasty 1993;8:341-6.

23. Muldoon MP, Padgett DE, Rothen R, Cady GW, Melillo AS. Failure of a non-porous-coated acetabular component inserted without cement in primary total hip arthroplasty. J Bone Joint Surg [Am] 1996;78-A:1486-90.

24. Journeaux SF, Morgan DAF, Donnelly WJ. Poor results of the Freeman uncemented metal-backed acetabular component: five- to nine-year results. J Bone Joint Surg [Br] 2000;82-B:185-7.

25. Livermore J, Ilstrup D, Morrey B. Effect of femoral head size on wear of the polyethylene acetabular component. J Bone Joint Surg [Am] 1990;72-A:518-28. 